\title{
ANALISIS PROSES PENGEMBANGAN E-LEARNING BERBASIS MOODLE V.3.1. PADA MATA KULIAH BELAJAR DAN PEMBELAJARAN
}

\author{
Anangga Widya Pradipta, Amy Nilam Wardathi \\ IKIP Budi Utomo Malang, Indonesia \\ Email: ananggawidya@gmail.com
}

\begin{abstract}
ABSTRAK
Tujuan penelitian yang telah dilakukan adalah untuk menghasilkan media pembelajaran berbantuan internet. Secara khusus penelitian ini bertujuan mendesain dan mengembangkan e-learning berbasis Moodle V.3.1.untuk meningkatkan pemahaman konsep mata kuliah Belajar dan Pembelajaran Program Studi Pendidikan Jasmani Kesehatan dan Rekreasi IKIP Budi Utomo Malang. Prosedur pengembangan meliputi 4 tahap utama yaitu perencanaan, desain, pengembangan dan evaluasi sumatif. Teknik pengumpulan data yang digunakan untuk mengolah maupun dan menginterpretasikan hasil tinjauan dan uji coba produk pengembangan bahan ajar yaitu teknik analisis kuantitatif. Analisis data kuantiatif digunakan untuk menguji validitas dan reliabilitas instrumen tes pemahaman konsep. Analisis data dijadikan acuan untuk memperbaiki atau merevisi produk. Hasil pengembangan berupa e-learning dengan software aplikasi moodle versi 3.1 dengan revisi versi 3.5.2 dengan alamat https://widyapradipta.com. Kelayakan produk e-learning dari Standar teknis memperoleh nilai $82,5 \%$ dengan kategori sangat layak. Standar isi dan konten memperoleh nilai $82 \%$ dengan kategori sangat layak dan standar desain visual memperoleh nilai 77,32\% dengan kategori layak. Hasil tes pemahaman konsep mahasiswa memperoleh nilai 83,6\% kategori sangat baik.
\end{abstract}

Kata kunci: E-learning berbasis Moodle V.3.1, Pemahaman Konsep

\begin{abstract}
The purpose of the research is to produce publications media assisted by the internet. This research is mainly conducted to design and develop Moodle V.3.1-based e-learning to improve the understanding of Learning and Learning subjects in the Health and Recreation Physical Education Study Program of IKIP Budi Utomo Malang. The development procedure includes 4 main stages, namely planning, design, development and evaluation of data. The data used to analyze the results and analysis for the development of teaching materials is quantitative analysis data. Data analysis was performed to test the validity and reliability of concept comprehension test instruments. Data analysis can be used to improve or revise products. The development results include e-learning with the Moodle version 3.1 application software with revised version 3.5.2 on the address https://widyapradipta.com. Feasibility of e-learning products from technical standards with a value of $82.5 \%$ with very feasible categories. Standard content and data content is $82 \%$ with very feasible categories and visual design standards achieved by $77.32 \%$ with decent categories. The results of the students' concept understanding test rose in the category of $83.6 \%$ in the very good category.
\end{abstract}

Keywords: Moodle V.3.1-Based E-learning, Concept Understanding

\section{PENDAHULUAN}

Perkembangan ilmu pengetahuan dan teknologi mendorong pendidikan tinggi untuk selalu mengadakan pemutakhiran proses pembelajaran yang berdampak pada proses penyajian isi mata kuliah dan bahan ajar yang digunakan. Salah satu proses penyajianya dapat dilakukan secara online melalui e-learning. Pemanfaatan e-learning dapat dilakukan dengan cara membuat course yang didalamnya berisi materi pembelajaran, multimedia, tugas-tugas, kuis, pengumuman serta 
tautan untuk pengayaan. Dosen juga bisa melakukan monitoring, komunikasi dan kerjasama. Disisi lain mahasiswa dapat mengunduh materi perkuliahan, tugas-tugas dan kuis serta berpartisipasi dalam forum dan chatting. E-learning biasanya mengacu pada penggunaan jaringan teknologi dan informasi melalui website untuk pembelajaran sehingga sedikit berbeda dengan pembelajaran tatap muka (Naidu, 2006:1). Pendapat tersebut sejalan dengan Sara (2014: 139-152) yang berpedapat bahwa e-learning merupakan pembelajaran yang disampaikan melalui perangkat digital seperti komputer, tablet bahkan smartphone dan berbentuk multimedia yang dapat di akses dari mana saja dan kapan saja.

Salah satu mata kuliah wajib dalam program studi pendidikan jasmani kesehatan dan rekreasi yaitu Belajar dan Pembelajaran. Mata kuliah ini merupakan mata kuliah teori dengan beban 3 SKS yang bertujuan memahami hakikat, prinsip-prinsip dasar, perkembangan dan problematika belajar masa kini. Sesuai dengan karakteristik materi mata kuliah belajar dan pembelajaran, mata kuliah ini berisi fakta, konsep dan generalisasi yang harus dikuasai mahasiswa, sehingga dalam mempelajari materi tersebut diperlukan pemahaman konsep tinggi yang tinggi, media pembelajaran dan waktu yang lebih fleksibel untuk belajar.

Berdasarkan studi pendahuluan dan analisis kebutuhan media yang digunakan, penggunaan media masih berada pada tataran kurang, yang dibuktikan dengan $80 \%$ mahasiswa menjawab perlu dikembangkan media pembelajaran dan 20\% mahasiswa berpendapat tidak perlu dikembangkan. Kecenderungan mahasiswa mengakses internet tinggi sekali, dibuktikan 30\% mahasiswa sangat sering mengakses internet, $60 \%$ mahasiswa sering mengakses internet dan $10 \%$ mahasiswa jarang mengakses internet. Sebagian besar mahasiswa mengakses internet untuk mendapatkan materi perkuliahan, dibuktikan dengan 62\% mahasiswa sangat sering mendapatkan materi perkuliahan di internet, 20\% mahasiswa sering mendapatkan materi perkuliahan dari internet dan $12 \%$ mahasiswa mendapatkan materi perkuliahan di internet. Perangkat yang digunakan mahasiswa untuk mengakses internet yaitu secara keseluruhan menjawab komputer/ laptop, 79.17\% menjawab smartphone, dan 20.33\% menjawab tablet.

Institusi telah mempunyai fasilitas internet yaitu hotspot area dan laboratorium komputer. Beberapa hambatan pembelajaran mata kuliah belajar dan pembelajaran di prodi PJKR IKIP Budi Utomo Malang yaitu materi perkuliahan disajikan menggunakan media yang sederhana sehingga mahasiswa kurang menunjukkan pemahaman konsepnya sebagai hasil belajar. Di sisi lain, dosen juga sulit mengelola kelas dan materi perkuliahan yang banyak sehingga jam perkuliahan tidak cukup.

Berdasarkan pengamatan dari media e-learning yang ada di IKIP Budi Utomo Malang, penggunaan e-learning berupa kumpulan materi dan soal yang tersimpan di server untuk sekedar upload-download materi dan soal ujian. Fasilitas pendukung pembelajaran menggunakan e-learning yang berupa diskusi, tes berbasis komputer dan video pembelajaran belum digunakan. Solusi untuk mengatasi permasalahan tersebut yaitu dengan 
mengembangkan media e-learning berbasis moodle V3.1. Materi dalam e-learning didesain dengan pendekatan pemahaman konsep yang terdiri dari mengklasifikasikan, menafsirkan pengalaman, mengumpulkan informasi dan menginterpretasikan pengalaman.

\section{METODE}

Penelitian yang dilaksanakan merupakan penelitian pengembangan. Prosedur pengembangan meliputi 4 tahap utama yaitu a) Planning yang berupa perencanaan sebelum produk awal ditentukan dan dikembangkan; b) Design berupa pengembangan ide-ide, melakukan analisis konsep dan tugas, lakukan deskripsi program awal; c) Development berupa pengembangan produk hingga validasi; d) Sumative Evaluation merupakan tahap evaluasi untuk mengetahui efektivitas e-learning terhadap pemahaman konsep sebelum dan sesudah diterapkan e-learning dikelas (Alessi dan Trollip, 2001:410).

Penelitian menggunakan beberapa instrument penelitian, yaitu dengan tes dan Kuesioner. Tes dilakukan untuk melihat kemampuan mahasiswa dtinjau dari pemahaman konsep secara keseluruhan setelah diberikan pembelajaran oleh dosen.

Kuesioner digunakan untuk memperoleh data kelayakan kualitas e-learning yang dikembangkan berdasarkan aspek materi dan media. Butir instrument dalam kuesioner disusun menggunakan Likert Scale. Langkah penyusunan kuesioner dilakukan berdasarkan kisi-kisi kemudian dilakukan validasi oleh expert judgement untuk menngetahui tingkat validitasnya. Soal tes digunakan untuk mengetahui tingkat pemahaman mahasiswa setelah belajar menggunakan media e-learning. Pretest dan posttest dengan soal yang sama namun disusun dan diberikan pada waktu yang berbeda

Data yang diperoleh dianalisis menggunakan teknik analisis data statistik deskriptif melalui tabel, diagram, penyajian rerata serta perhitungan persentase pencapaian tes pemahaman konsep. Sugiyono (2012: 199-200) berpendapat bahwa teknik analisis data statistik deskriptif adalah statistik yang digunakan untuk menganalisis data dengan cara mendeskripsikan atau menggambarkan data yang telah terkumpul sebagaimana adanya tanpa bermaksud membuat kesimpulan berlaku untuk umum atau generalisasi.

Hasil analisis data deskriptif kuantitatif kemudian dimaknai secara kualitatif menggunakan kriteria kategori penilaian ideal melalui konversi skor 5 skala. Kriteria kategori penilaian ideal disajikan pada tabel berikut ini:

Tabel 1 Pengambilan Keputusan Revisi E-learning Berbasis Moodle v 3.1.

\begin{tabular}{lll}
\hline Tingkat Pencapaian (\%) & Kualifikasi & Keterangan \\
\hline $81-100$ & Baik Sekali & Tidak perlu revisi \\
$61-80$ & Baik & Tidak perlu revisi \\
$41-60$ & Cukup & Direvisi \\
$21-40$ & Kurang & Direvisi \\
$0-20$ & Sangat baik & Direvisi \\
\hline
\end{tabular}

Hasil tes pemahaman konsep belajar dan pembelajaran: seberapa menunjukkan efektifitas e-learning besar presentase mahasiswa yang telah ditinjau dari aspek pemahaman konsep mencapai nilai kriteria ketuntasan 
minimal (KKM) dan nilai kebermaknaan belajar (effect size).

\section{HASIL DAN PEMBAHASAN}

E-learning dikembangkan menggunakan aplikasi Moodle versi 3.1. dengan update versi 3.5.2 yang dapat didownload dari http://www.moodle. org. Aplikasi Moodle diupload pada website http://www.widyapradipta.com. Versi moodle yang dikembangkan dapat dilihat pada gambar berikut:

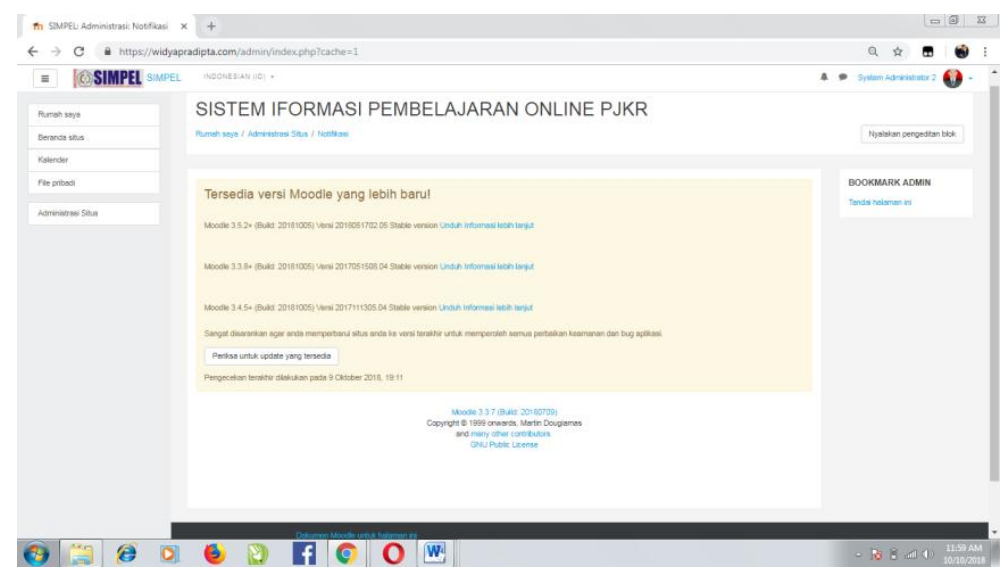

Gambar 1.Tampilan Halaman Depan

Berdasarkan gambar tersebut dapat pembaruan yang tersedia yaitu versi dideskripsikan bahwa pada aplikasi Moodle 3.4.5+, Moodle 3.3.8+ dan versi moodle yang telah direncanakan pada versi 3.1. memerlukan pembaruan pada versi 3.3.7. Sesuai tanggal yang telah tercantum, aplikasi moodle telah diunggah pada tanggal 9 Juli 2018. Aplikasi yang telah diunggah memiliki

\section{Moodle 3.5.2+.}

Langkah berikutnya mendesain tampilan antarmuka (interface). Halaman login E-Learning. Halaman login e-learning dapat dilihat pada gambar berikut:

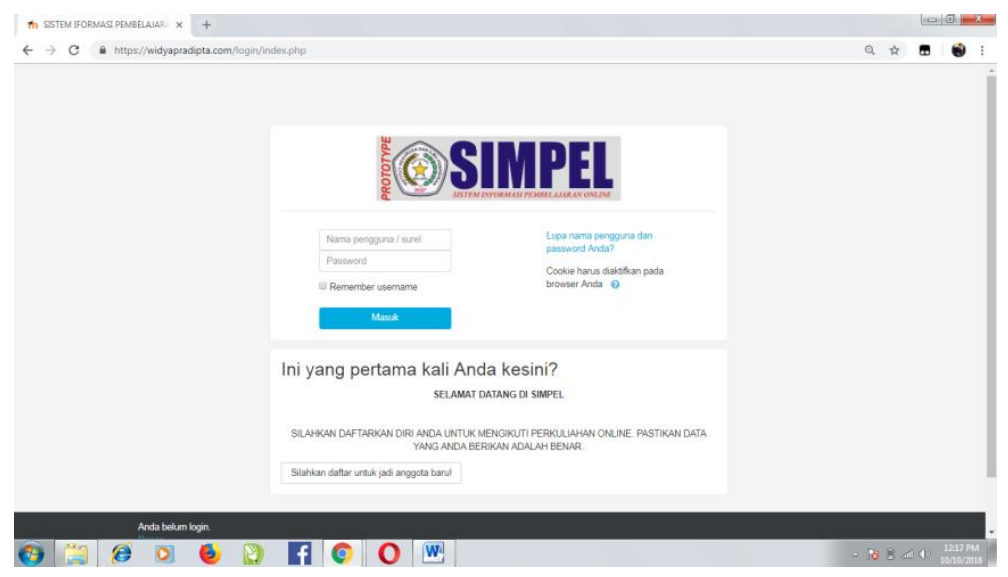

Gambar 2.Halaman Login (Masuk) 
Berdasarkan gambar tersebut kata sandi. Bagi pengguna yang belum dapat dikemukakan bahwa e-learning memiliki akun pembelajaran online diberinama "SIMPEL" merupakan dapatmendaftardengan mengklik button akronim dari sistem informasi "Silahkan daftar untuk menjadi anggota pembelajaran online. Pengguna dapat baru". Formulir online pendaftaran mengaplikasikan dengan mengetikkan e-learning dapat dilihat pada gambar nama pengguna/surel serta mengetikkan berikut.

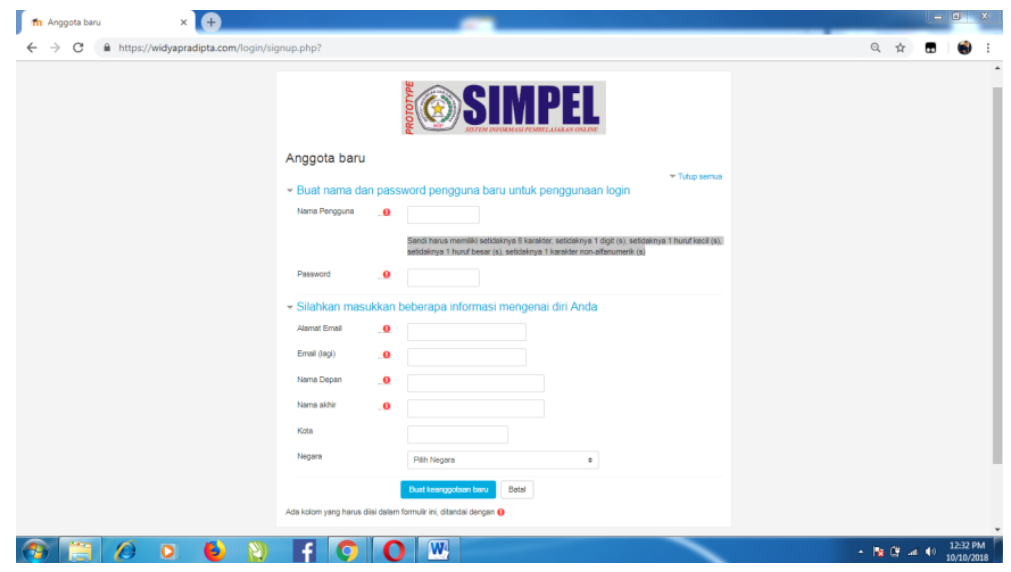

Gambar 3. Formulir Pendaftaran Pengguna

Berdasarkan gambar tersebut, 1 karakter non-alfanumerik. Data diri pengguna baru dapat membuat nama pengguna meliputi e-mail yang aktif, dan pengguna baru untuk login. Nama nama depan, nama akhir, kota tempat pengguna memiliki ketentuan nama tinggal dan nama negara.

yang belum pernah digunakan. Kata Jika pengguna lupa kata sandi untuk sandi memiliki ketentuan panjang kata login, maka pengguna dapat mengklik sandi minimal 8 karakter setidaknya button "Lupa nama pengguna dan kata 1 digit, setidaknya 1 huruf kecil, sandi anda?". Button tersebut memiliki setidaknya 1 huruf besar, setidaknya tampilan seperti gambar berikut:

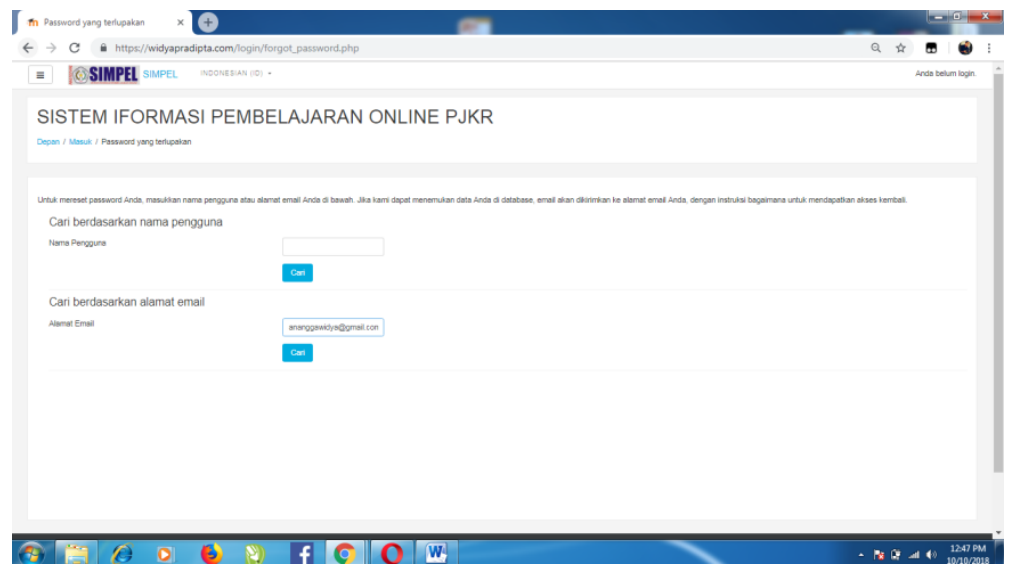

Gambar 4. Formulir Online Lupa Kata Sandi

Anangga Widya Pradipta, Amy Nilam Wardathi, Analisis Proses Pengembangan E-Learning Berbasis Moodle V.3.1. Pada Mata Kuliah Belajar dan Pembelajaran 
Berdasarkan gambar tersebut pengguna. Autoreply dari e-learning pegguna dapat mengatur ulang dengan terkadang juga masuk dalam kolom mengetikkan email yang digunakan spam pana e-mail pengguna, hal untuk mendaftar dan secara autoreply ini dikarenakan tergantung pada e-learning akan mengirimkan url dan pengaturan keamanan e-mail pengguna. hanya berlaku selama 30 menit untuk Hasil ujicoba reset kata sandi e-learning mengatur ulang kata sandi dan nama sebagai berikut:

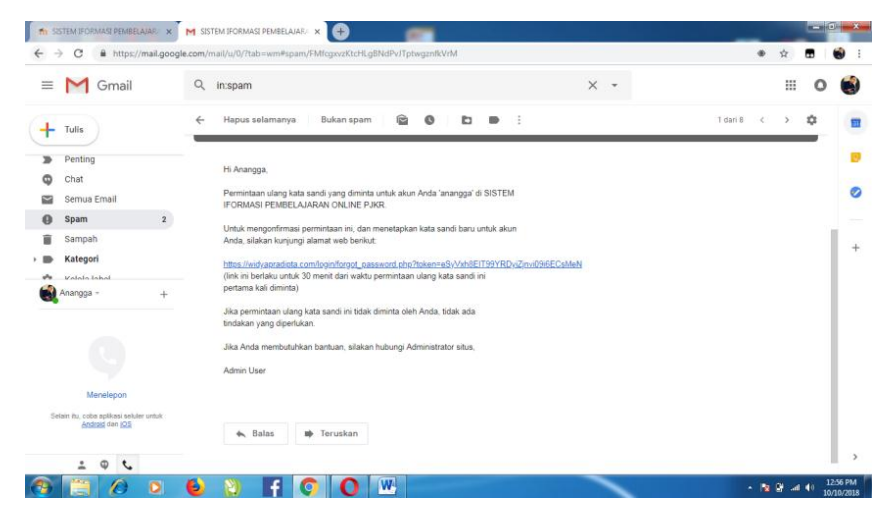

Gambar 5. Permintaan Atur Ulang Kata Sandi

Data pengguna e-learning terdapat terlihat nama depan dan nama akhir, 16 orang pengguna. Data pengguna ada alamt e-mail, kota, Negara dan waktu pada administrasi situs secara umum akses terakhir.

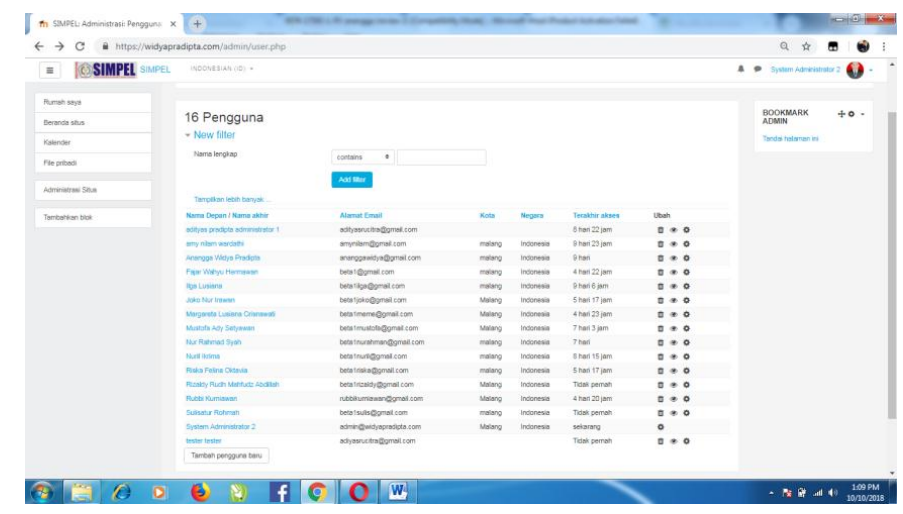

Gambar 6. Daftar Pengguna E-learning

Secara khusus detil pengguna memiliki tampilan sebagai berikut:

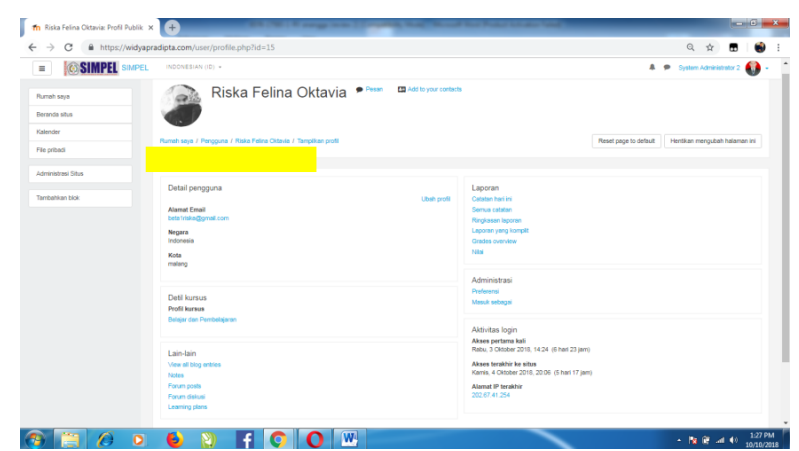

Gambar 7. Tampilan Detil Pengguna E-learning

JINoP (Jurnal Inovasi Pembelajaran), Volume 4, Nomor 2 , November 2018, hal 113-122 
Berdasarkan gambar detil pengguna, dapat dideskripsikan bahwa pengguna memiliki detail akun nama pengguna, letak kota dan negara perkuliahan yang diikuti, laporan administrasi, akses pertama dan terakhir serta alamat internet protokol perangat keras terakhir yang digunakan.

Secara khusus uji coba untuk mata kuliah belajar dan pembelajaran memiliki jumlah pengguna 11 0rang pengguna terdaftar.

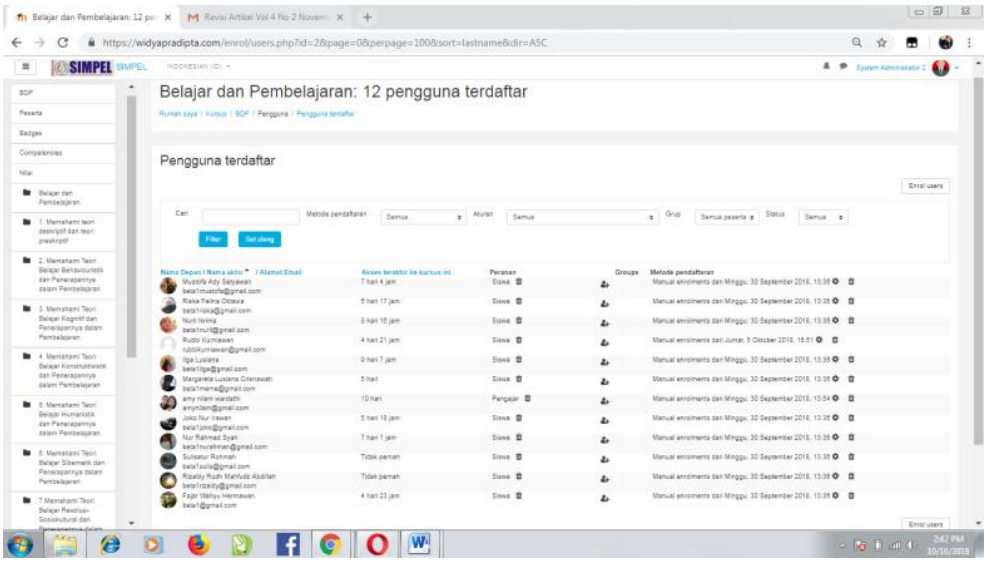

\section{Gambar 7. Tampilan Detil Pengguna Terdaftar Mata Kuliah Belajar dan Pembelajaran}

Mata Kuliah Belajar dan belajar behaviouristik, teori belajar pembelajaran memiliki delapan kognitif, teori belajar konstruktivistik, pokok bahasan yaitu memahami teori teori belajar humanistik, teori belajar pembelajaran dan penerapannya. sibernetik, teori belajar kecerdasan Teori teori tersebut terdiri dari teori ganda. deskriptif dan teori preskriptif, teori

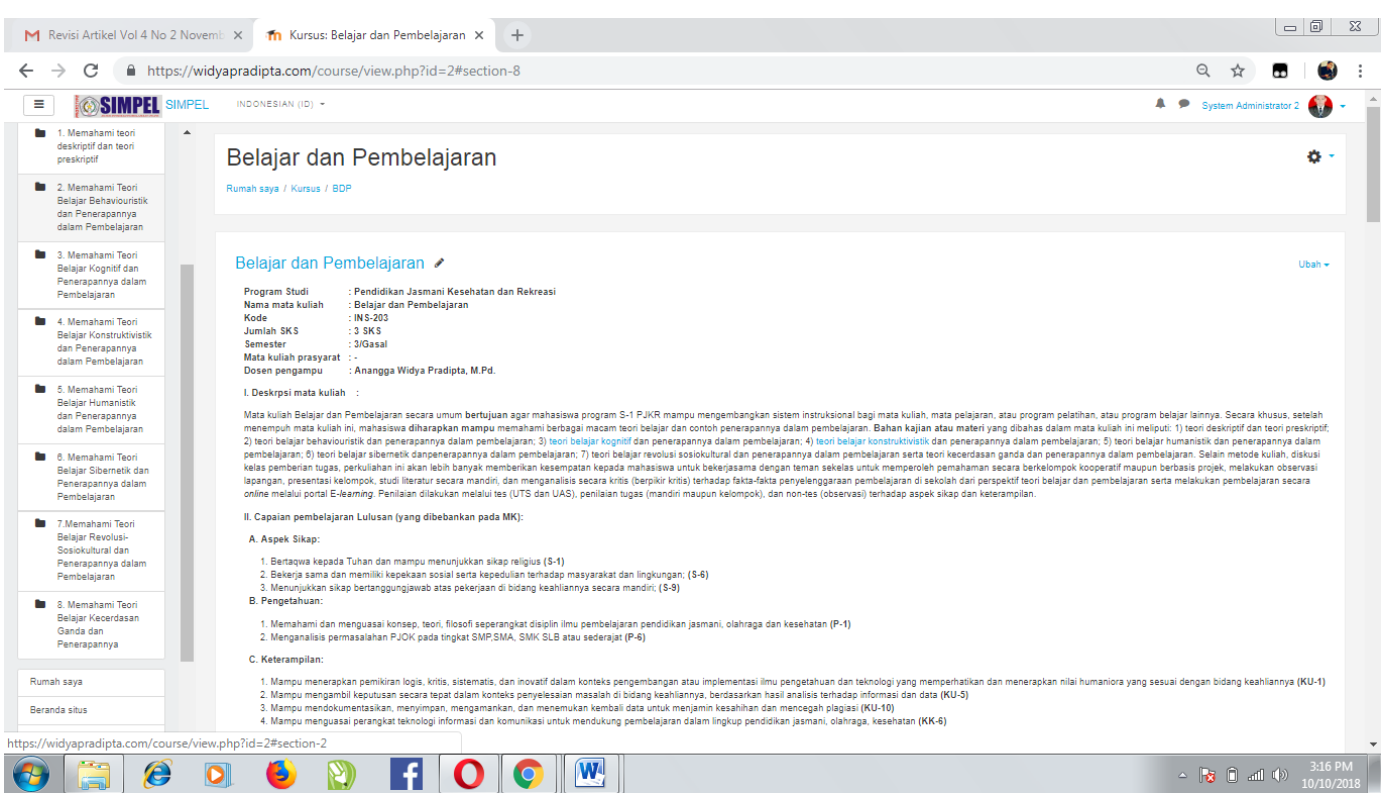

Gambar 8.Tampilan Halaman Isi Materi

Anangga Widya Pradipta, Amy Nilam Wardathi, Analisis Proses Pengembangan E-Learning Berbasis Moodle V.3.1. Pada Mata Kuliah Belajar dan Pembelajaran 
E-learning ini juga dapat diakses android: menggunakan aplikasi moodle mobile

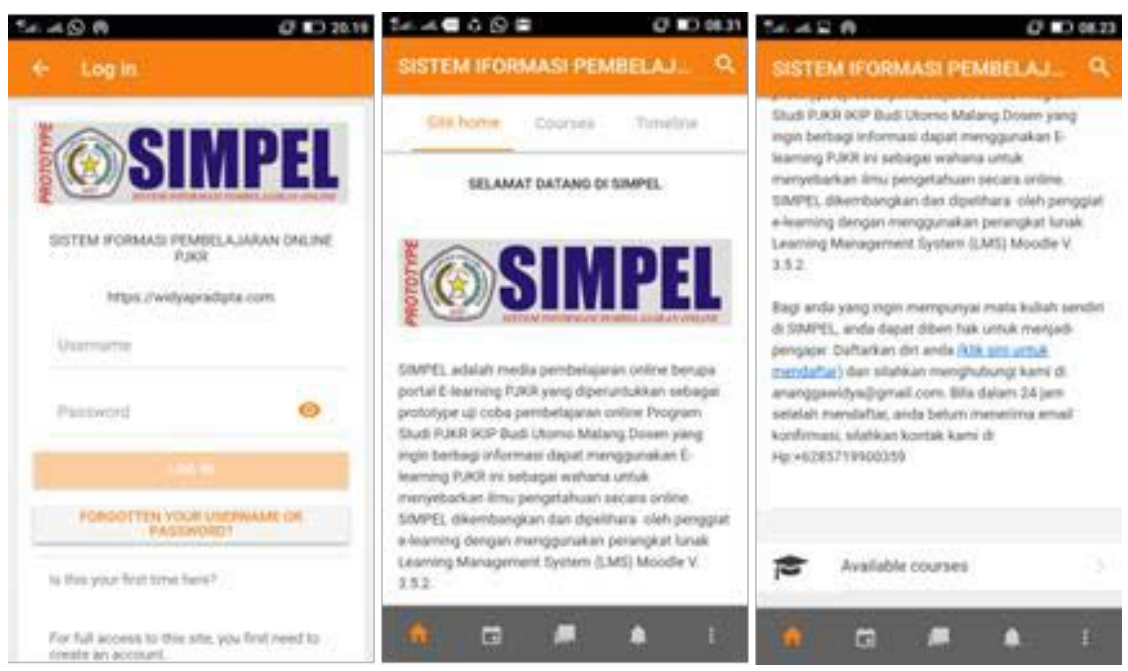

Gambar 9.Tampilan Halaman Login, Halaman Depan dan Perkuliahan yang Tersedia Meggunakan Sistem operasi Android Lollipop (Android 5.1)
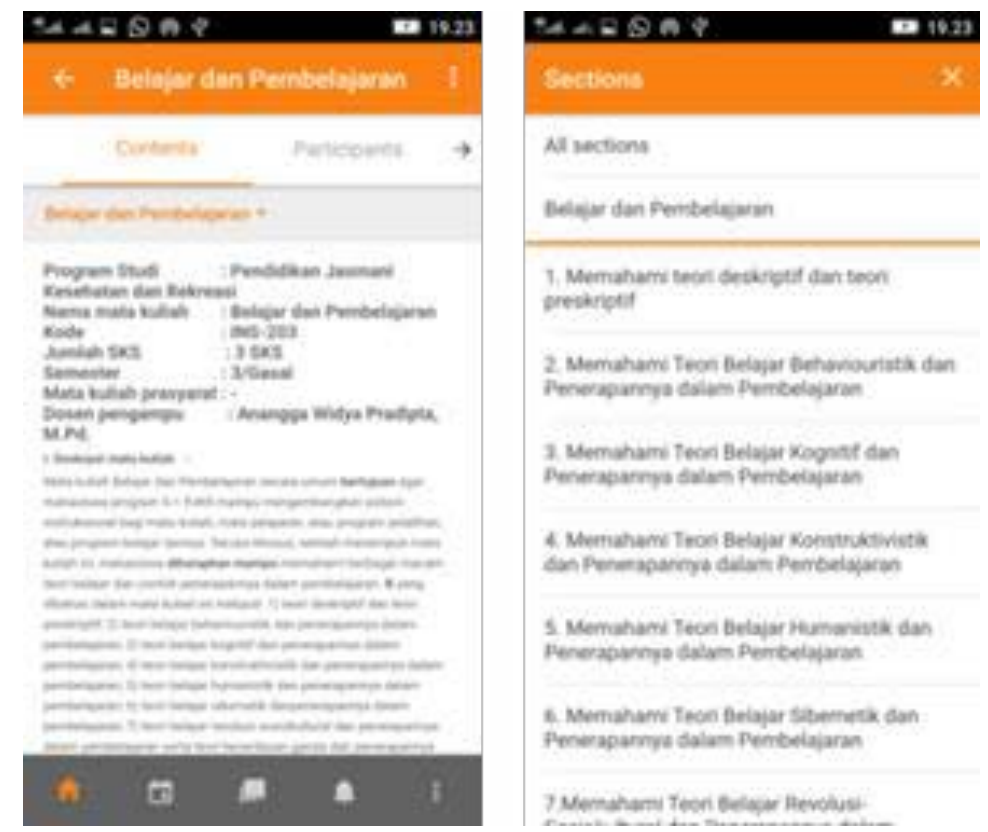

\section{Gambar 10.Tampilan Halaman Perkuliahan Menggunakan Sistem operasi Android Lollipop (Android 5.1)}

Setelah e-learning tersusun secara teknis, isi materi dan visual maka diajukan kepada validator untuk diukur kelayakannya. Penilaian validator terhadap e-learning dirangkum dalam tabel, kemudian dijumlahkan nilai per aspek dan di lakukan perhitungan persentase. 
Hasil validasi ahli media dan desain dihitung tingkat pencapaian persentase kelayakan produk e-learning dari standar teknis memperoleh nilai $82,5 \%$ dengan kategori sangat layak. Standar isi dan konten memperoleh nilai $82 \%$ dengan kategori sangat layak dan standar desain visual memperoleh nilai $77,32 \%$ dengan kategori layak. Hasil analisis data melalui angket atau tanggapan pada lembar validasi, digunakan untuk merevisi produk bahan ajar Belajar dan pembelajaran. Saran dari ahli terkait segi teknis hendaknya ditambahkan lebih detil pada video pembelajaran pada tiap subpokok bahasan. Saran dari ahli materi terkait isi dan konten navigasi dan petunjuk pembelajaran hendaknya dibagi pada sub-sub pokok bahasan yang lebih kecil agar lebih mudah dipelajari.
Tahap terakhir adalah evaluasi. Pada tahap evaluasi terjadi pada setiap empat tahap diatas (analisis, desain, development dan implementasi). Evaluasi yang terjadi pada tahap diatas adalah evaluasi formatif karena tujuannya untuk kebutuhan revisi. Tahapan ini meliputi penilaian terhadap pengembangan e-learning berbasis moodle v 3.1. Untuk mata kuliah belajar dan pembelajaran dengan melakukan klarifikasi data yang diperoleh dari lembar validasi dan angket berupa tanggapan serta saran dari uji coba tes alpa. Setelah melakukan uji ahli dilakukan uji efektifitas e-learning berbasis moodle $\mathrm{v}$ 3.1. Untuk mata kuliah belajar dan pembelajaran kepada mahasiswa baik perorangan maupun kelompok sedang.

Tabel 2. Hasil Tes Pemahaman Konsep

\begin{tabular}{lll}
\hline Tingkat Pencapaian (\%) & Kualifikasi & Keterangan \\
\hline Fajar Wahyu Hermawan & 82 & Sangat Baik \\
Mustofa Ady Setyawan & 80 & Sangat Baik \\
Nuril Ikrima & 90 & Sangat Baik \\
Nur Rahmad Syah & 88 & Sangat Baik \\
Riska Felina Oktavia & 92 & Sangat Baik \\
Rizaldy Rudh Mahfudz A. & 80 & Sangat Baik \\
Joko Nur Irawan & 80 & Sangat Baik \\
Ilga Lusiana & 80 & Sangat Baik \\
Sulisaturrohmah & 82 & Sangat Baik \\
Margareta Lusiana C. & 82 & Sangat Baik \\
\hline Rata-rata & 83.6 & Sangat Baik \\
\hline
\end{tabular}

\section{SIMPULAN}

Berdasarkan tahap penelitian yang telah dilakukan dapat ditarik kesimpulan. Hasil validasi ahli media dan desain dihitung tingkat pencapaian persentase kelayakan produk e-learning dari standar teknis memperoleh nilai $82,5 \%$ dengan kategori sangat layak. Standar isi dan konten memperoleh nilai $82 \%$ dengan kategori sangat layak dan standar desain visual memperoleh nilai $77,32 \%$ dengan kategori layak.

Saran penelitian perumusan CPL dan CPMK untuk penyusunan e-learning hendaknya mencakup tingkat ranah kognitif rendah dan tinggi untuk melatih kemampuan kognitif mahasiswa. Penyusunan teks penyerta harus mampu membangkitkan pemahaman mahasiswa untuk membaca 
dan mempelajarinya, salah satunya dengan memperbaiki kualitas gambar ilustrasi yang digunakan. Jumlah validator ahli untuk aspek materi, dan materi disarankan lebih dari satu orang agar memperleh lebih banyak saran dan an bagi perbaikan bahan ajar. Dilanjutkan pada uji coba kelompok besar (klasikal) agar memperoleh lebih banyak saran dan perbaikan e-learning.

\section{DAFTAR PUSTAKA}

Alessi, S. M \& Trollip, R. S. (2001). Multimedia for Learning: Methods and development. Massachusetts: A Pearson Education.
Naidu, S. (2006). E-Learning " $A$ Guideebook of Principles, Procedures and Practices". Melbourne: Commonwealth of Learning.

Sara, C., \& Mukminan. (2014). Pengembangan E-Learning Mata Kuliah Aplikasi Komputer 2 Di Program Studi Pendidikan Sejarah Universitas Flores. Jurnal Inovasi Teknologi Pendidikan, Online 1(1), 139-152. JITP:UNY. (https:// journal.uny.ac.id/index.php/jitp/ article/view/2525) diakses 10 oktober 2018.

Sugiyono. (2012). Metode Penelitian Kombinasi (Mixed Methods). Bandung: Alfabeta. 